\title{
Chemotherapy overcomes TRAIL-R4-mediated TRAIL resistance at the DISC level
}

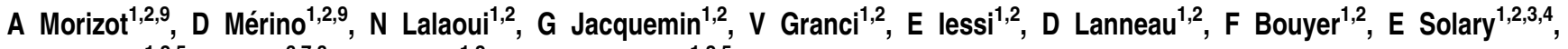 \\ B Chauffert ${ }^{1,2,5}$, P Saas $^{6,7,8}$, C Garrido $^{1,2}$ and $O$ Micheau $^{\star, 1,2,5}$
}

TNF-related apoptosis-inducing ligand or Apo2L (Apo2L/TRAIL) is a promising anti-cancer drug owing to its ability to trigger apoptosis by binding to TRAIL-R1 or TRAIL-R2, two membrane-bound receptors that are often expressed by tumor cells. TRAIL can also bind non-functional receptors such as TRAIL-R4, but controversies still exist regarding their potential to inhibit TRAIL-induced apoptosis. We show here that TRAIL-R4, expressed either endogenously or ectopically, inhibits TRAIL-induced apoptosis. Interestingly, the combination of chemotherapeutic drugs with TRAIL restores tumor cell sensitivity to apoptosis in TRAIL-R4-expressing cells. This sensitization, which mainly occurs at the death-inducing signaling complex (DISC) level, through enhanced caspase-8 recruitment and activation, is compromised by c-FLIP expression and is independent of the mitochondria. Importantly, TRAIL-R4 expression prevents TRAIL-induced tumor regression in nude mice, but tumor regression induced by TRAIL can be restored with chemotherapy. Our results clearly support a negative regulatory function for TRAIL-R4 in controlling TRAIL signaling, and unveil the ability of TRAIL-R4 to cooperate with c-FLIP to inhibit TRAIL-induced cell death. Cell Death and Differentiation (2011) 18, 700-711; doi:10.1038/cdd.2010.144; published online 12 November 2010

TNF-related apoptosis-inducing ligand or Apo2L (TRAIL) is a promising tool for cancer therapy, owing to its ability to eradicate tumor cells while sparing normal cells. ${ }^{1}$ TRAIL is a type II transmembrane protein, whose binding to its agonistic receptors, namely TRAIL-R1 (DR4) and TRAIL-R2 (DR5, TRICK2 or KILLER), triggers apoptosis in a p53-independent manner. Engagement of TRAIL agonistic receptors induces the formation of a molecular platform called the DISC (death-inducing signaling complex) within minutes, through homotypic interactions. ${ }^{2}$ This platform includes the adapter protein FADD and caspase-8, an initiator caspase that is activated and subsequently released from the DISC to the cytosol for dismantling of the cells. The amount of caspase- 8 generated within the DISC in type I cells is sufficient to trigger apoptosis through the direct activation of the effector caspase-3. Type II cells require the engagement of a mitochondrial amplification loop, which is activated by caspase-8-dependent cleavage of Bid, a $\mathrm{BH} 3-$ only protein that targets the intrinsic pathway through Bax and Bak, allowing the formation of the apoptosome. However, enforced aggregation of TRAIL agonistic receptors in these cells enhances caspase-8 activation at the DISC level and overcomes mitochondrial checkpoints. ${ }^{3}$ Likewise, enhanced caspase-8 recruitment and activation at the TRAIL DISC by chemotherapeutic drugs has been associated with the restoration of TRAIL sensitivity in hepatocellular and colon carcinomas. ${ }^{4,5}$
Cellular resistance to TRAIL-induced cell death arises from a large variety of events, ranging from defects in DISC formation, or inhibition of more distal events, including mitochondrial block. ${ }^{6,7}$

TRAIL-induced cell death can be specifically inhibited by two membrane-bound antagonistic receptors, TRAIL-R3 (DcR1, LIT or TRID) or TRAIL-R4 (DcR2 or TRUNDD). ${ }^{2}$ These receptors have been shown to be expressed and to prevent TRAIL-induced cell death in various human primary tumor cells, including lymphomas, lung, breast and prostate carcinomas, ${ }^{8-10}$ but the inhibitory potential of this receptor still remains controversial. ${ }^{11}$ Although TRAIL-R3 is a GPI-anchored receptor that sequesters TRAIL into lipid rafts, TRAIL-R4 interacts with TRAIL-R2 within the DISC, and impairs caspase- 8 processing, ${ }^{12}$ thus, inhibiting TRAILinduced apoptosis. ${ }^{13,14}$

The efficacy of recombinant hAPO2L/TRAIL in association with chemotherapy is evaluated in ongoing clinical trials. ${ }^{1}$ It remains unknown whether TRAIL-R4 expression may compromise the efficacy of TRAIL.

We demonstrate here that TRAIL-R4 efficiently inhibits TRAIL, and that chemotherapeutic drugs can overcome this resistance. Restoration of apoptosis primarily occurs at the membrane level, irrespective of the mitochondria, through enhanced caspase-8 recruitment and activation at the TRAIL DISC. TRAIL-R4 expression also impairs TRAIL-induced tumor regression in vivo, but sequential treatments associating

\footnotetext{
${ }^{1}$ INSERM, U866, Dijon, F-21079 France; ${ }^{2}$ Faculty of Medicine and Pharmacy, Université de Bourgogne, Dijon, F-21079, France; ${ }^{3}$ INSERM, U1009, Villejuif, F-94805, France; ${ }^{4}$ Institut Gustave Roussy, University of Paris XI, Villejuif, F-94805, France; ${ }^{5}$ Centre Georges-François Leclerc, Dijon, F-21000, France; ${ }^{6}$ INSERM, U645, Besançon, F-25020, France; ${ }^{7}$ EFS Bourgogne Franche Comté, Besançon, Plateforme BioMonitoring, F-25020, France and ${ }^{8}$ University of Franche-Comté, Besançon, F-25020, France

${ }^{*}$ Corresponding author: O Micheau, Faculty of Medicine and Pharmacy, Mort Cellulaire et Cancer, INSERM U866, 7, Bd Jeanne d'Arc, Dijon F-21079, France.

Tel: + 3338039 3468; Fax: + 3338039 3434; E-mail: omicheau@u-bourgogne.fr

${ }^{9}$ These authors contributed equally to this work.

Keywords: TRAIL; TRAIL-R4; c-FLIP; chemotherapy; apoptosis

Abbreviations: 5FU, 5-fluorouracil; CDDP, cisplatin; DISC, death-inducing signaling complex; TRAIL-R, trail Receptor ; VP16, etoposide

Received 07.7.10; revised 07.9.10; accepted 08.10.10; Edited by S Nagata; published online 12.11.10
} 
CDDP and TRAIL prevent tumor growth in nude mice. Altogether, our results demonstrate that TRAIL-R4 is a negative regulator of TRAIL, whose inhibitory function can be overcome by chemotherapy.

\section{Results}

TRAIL and chemotherapeutic drugs synergistically induce apoptosis in TRAIL-R4-expressing cells. We have demonstrated previously that, ectopic expression of TRAIL-R4 impairs TRAIL-induced cell death through the formation of a heteromeric complex with TRAIL-R2, leading to the inhibition of caspase-8 activation within the TRAIL DISC. ${ }^{12}$ Owing to the ability of TRAIL-R4 to inhibit TRAILinduced cell death, we evaluated whether its expression may compromise combination therapies associating TRAIL with conventional chemotherapeutic drugs. To test this hypothesis, TRAIL-R4 was ectopically expressed using retroviruses in three TRAIL-sensitive tumoral cell lines, HeLa, Jurkat and SW480. Cell surface expression was assessed by flow cytometry (Figure 1a and b). TRAIL-R4 inhibited TRAIL-induced apoptosis in these cells (Figure 1c and d). Strikingly, TRAIL-R4 also inhibited death induced by chemotherapeutic drugs in some cell lines. Pre-treatment with pharmacological concentrations of CDDP, VP16 for $3 \mathrm{~h}$ or 5FU for $72 \mathrm{~h}$, however, restored TRAIL sensitivity in these cells (Figure $1 \mathrm{c}$ and $\mathrm{d}$ ). Similar results were obtained in the B-lymphoma cell line VAL, in which the cells are poorly sensitive to TRAIL-induced cell death (Figure 1e). VAL cells endogenously express TRAIL-R4 at the cell surface and high levels of $\mathrm{Bcl}-2$, because of the $t(14 ; 18)$ chromosomal translocation (Figure $1 \mathrm{f}$ and $\mathrm{g}$ ). Cells sensitivity to TRAIL-induced cell death was restored in VAL cells after pre-treatment with CDDP, VP16, or 5FU (Figure 1e). siRNA-mediated downregulation of TRAIL-R4 or Bcl-2 expression in VAL cells also restored sensitivity to TRAIL (Figure $1 \mathrm{f}$ and $\mathrm{g}$ ), demonstrating that both TRAIL-R4 and Bcl2 are functional in these cells.

Sequential chemotherapy and TRAIL treatments restore caspase activation. Chemotherapeutic drugs enhanced caspase activation upon TRAIL stimulation (Figure 2a) without changing TRAIL receptor expression (Supplementary Figure S1). In HeLa control cells, TRAIL alone triggered the activation of caspase-8, caspase-9 and caspase-3, and induced Bid and PARP cleavage, as demonstrated by the disappearance of their proform or the appearance of cleaved fragments (Figure 2a). However, in HeLa cells expressing TRAIL-R4 (H-TRAIL-R4 cells), TRAIL induced only a modest cleavage of caspase-8 and caspase9 , resulting in the poor activation of caspase-3 (Figure 2a). Pre-treatment of these cells with CDDP, VP16, or 5FU restored caspase-3 activation upon TRAIL stimulation, as demonstrated by the appearance of the caspase- 3 p17 fragment and an increase in PARP cleavage (Figure 2a). Restoration of caspase-3 activation by chemotherapeutic drugs in HeLa-TRAIL-R4 cells was associated with partial activation of both caspase-8 and caspase-9 (Figure 2a).

Activation of the mitochondrial intrinsic pathway is not required to restore sensitivity to TRAIL in response to chemotherapy. As most chemotherapeutic drugs engage the mitochondrial pathway to trigger apoptosis, we next analyzed its contribution with regard to chemotherapymediated sensitization to TRAIL-induced cell death. TRAIL stimulation in control HeLa cells triggered the activation of the intrinsic pathway, as evidenced by the disappearance of Bid (Figure 2a), the release of cytochrome $c$, Smac/DIABLO and omi to the cytosol (Figure $2 b$ ), and by the activation of Bax (Figure 2d and e). Release of cytochrome $c$, Smac/ DIABLO and omi were much weaker in H-TRAIL-R4 cells as compared with control cells (Figure 2c), however, chemotherapy combined with TRAIL nearly completely restored Bax activation in these cells (Figure $2 \mathrm{~d}$ and $\mathrm{e}$ ). Overexpression of $\mathrm{Bcl}-2$ or $\mathrm{Bcl}-\mathrm{xL}$ in $\mathrm{H}$-TRAIL-R4 failed to protect cells from TRAIL-induced apoptosis after chemotherapy (Figure $3 a$ and b). These results are consistent with the demonstration that chemotherapeutic drugs can restore TRAIL sensitivity in VAL cells, despite large amounts of $\mathrm{Bcl}-2$ expression (Figure 1f). To determine the role of Bax in drug-mediated sensitization to TRAILinduced cell death, we performed the same experiments in the Bax-deficient or parental WT HCT116 cells engineered to express TRAIL-R4 (Figure 3c). TRAIL-mediated apoptosis in HCT116 cells was shown to rely on Bax but not Bak activation. ${ }^{15}$ According to these findings, TRAIL alone, or simultaneous combinations of TRAIL and 5FU, failed to induce apoptosis in Bax-deficient cells (Figure $3 d$ and

Figure 1 Chemotherapeutic drugs restore TRAIL-induced cell death in TRAIL-R4-expressing cells. (a) and (b), HeLa, Jurkat or SW480 cancer cell lines were infected with empty vector (H-Ctl, J-Ctl or SW-Ctl) or with a vector encoding TRAIL-R4 (H-TRAIL-R4, J-TRAIL-R4 or SW-TRAIL-R4). Expression of TRAIL receptors was analyzed by flow cytometry (gray line) against an isotype control (filled curve). (c) and (d), control cells or TRAIL-R4-expressing cells were stimulated with His-TRAIL (500 ng/ml, $6 \mathrm{~h}$ ), Cisplatin (CDDP, $20 \mu \mathrm{M}, 3 \mathrm{~h}$ ), etoposide (VP16, $10 \mu \mathrm{M}, 3 \mathrm{~h}$ ) or 5 -fluorouracil (5FU, $1 \mu \mathrm{g} / \mathrm{ml}, 72 \mathrm{~h}$ ). Apoptosis was evaluated after $6 \mathrm{~h}$ (TRAIL), $48 \mathrm{~h}$ (CDDP or VP16) or $72 \mathrm{~h}(5 \mathrm{FU})$ by Hoechst staining in HeLa (white), Jurkat (gray) or SW480 (black). Sequential stimulation with chemotherapeutic drugs and TRAIL was performed as follows. Cells were pre-treated with CDDP or VP16 for $3 \mathrm{~h}$, in serum-free medium, then washed and allowed to recover at $37^{\circ} \mathrm{C}$ in complete medium for $48 \mathrm{~h}$ before stimulation with His-TRAIL $(500 \mathrm{ng} / \mathrm{ml})$ for an additional $6 \mathrm{~h}$. Alternatively, cells were stimulated for $72 \mathrm{~h}$ with $5 \mathrm{FU}$, then His-TRAIL for $6 \mathrm{~h}$. (e) VAL cell sensitivity to His-TRAIL, chemotherapy or sequential treatments was analyzed as described above. (f) Deregulation of TRAIL-R4 expression in VAL cells using three different siRNAs (scramble siRNA, Src; TRAIL-R4 siRNA, \#1, \#2 and \#3) as analyzed by Facs for TRAIL-R4 expression using an anti-TRAIL-R4 antibody (gray line) or a control isotype (filled curved). The effect of TRAIL-R4 downregulation was assessed by Hoechst staining $6 \mathrm{~h}$ after His-TRAlL treatment $(500 \mathrm{ng} / \mathrm{ml})$, scramble (white) and TRAlL-R4 siRNA (\#1 gray; \#2 dashed and \#3 black). (g) Bcl-2 expression in VAL cells after transfection with the scramble siRNA ( $\mathrm{Src}$ ) or the Bcl-2 siRNA (Bcl-2) and corresponding Hoechst staining $6 \mathrm{~h}$ after His-TRAlL treatment $(500 \mathrm{ng} / \mathrm{ml}), \mathrm{Bcl}-2$ siRNA (in black) or a scramble siRNA (in white). These results are representative of at least three independent experiments. Mean percentage of apoptotic cells and S.D. shown (mean \pm S.D.). Differences between selected groups were compared by non-parametric analysis of variance (ANOVA) with Bonferroni post hoc multiple comparison test, ${ }^{* \star *} P<0.001$. Molecular size markers are shown on the right in $\mathrm{kDa}$. (For figure refer next page) 
Supplementary Figure S2). Nevertheless, pre-treatment for $72 \mathrm{~h}$ with $5 \mathrm{FU}$ before adding TRAIL efficiently induced cell death in these cells (Figure 3d). Likewise, treating Baxdeficient cells sequentially for $3 \mathrm{~h}$ with CDDP or VP16, and stimulating with TRAIL, $48 \mathrm{~h}$ after the onset of the treatment in drug-free medium (see Materials and Methods) restored TRAIL-induced apoptosis (Figure 3d). As in HeLa cells, sequential use of chemotherapy and TRAIL afforded sensitization to TRAIL-induced cell death in Bax-proficient cells expressing TRAIL-R4 ectopically (Figure 3d). However,

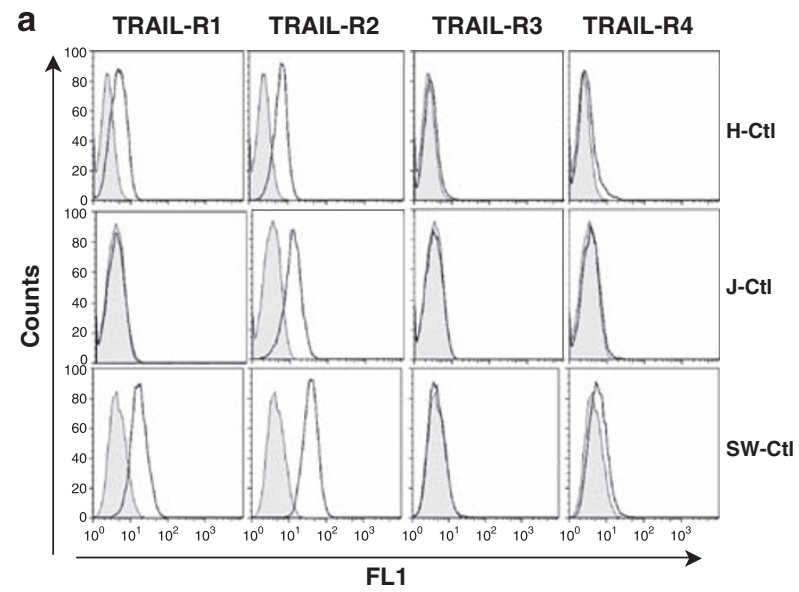

C

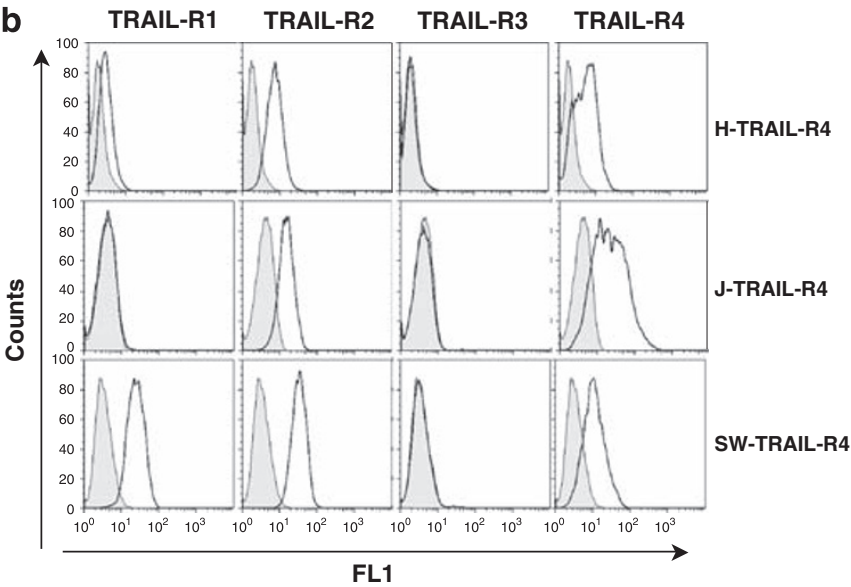

d

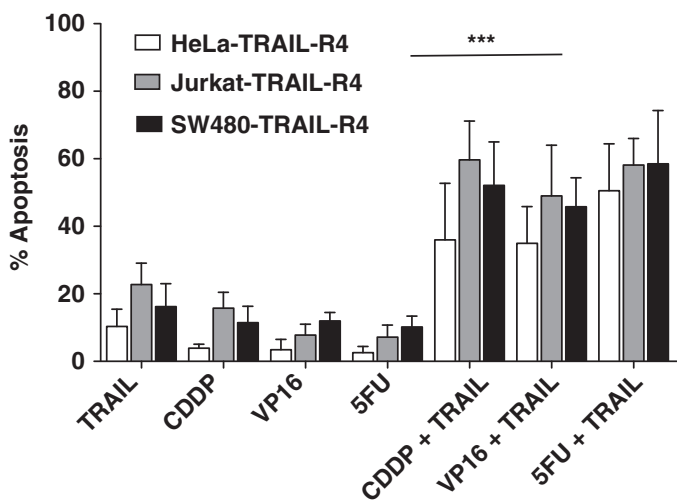

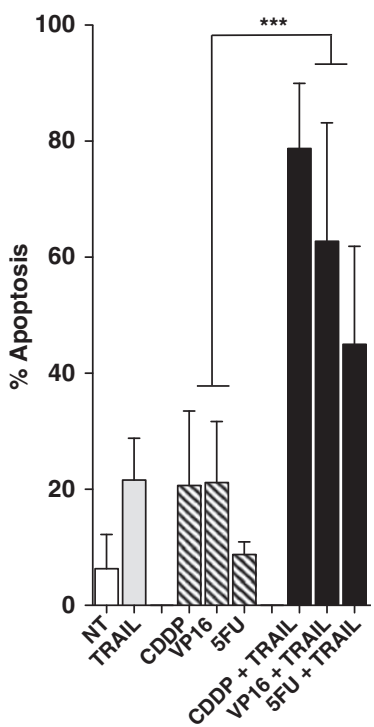

f
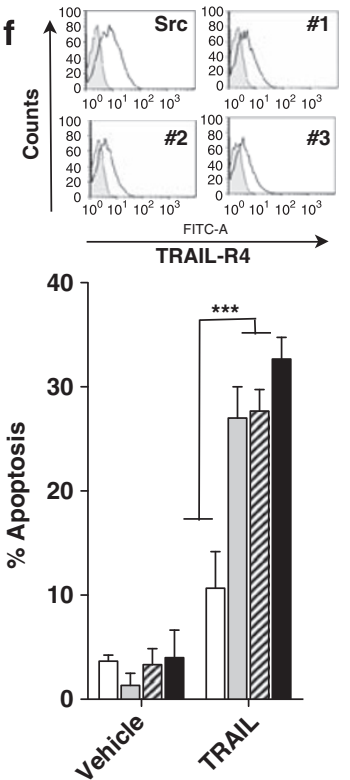

g
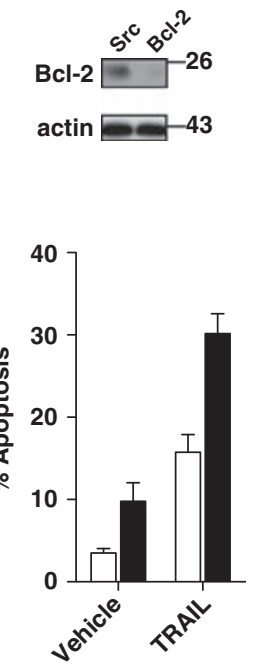

Figure 1 Continued. (For caption refer previous page) 
in the absence of Bax, TRAIL-R4 overexpression induced resistance to TRAIL after CDDP or VP16 pretreatment, but not upon 5FU stimulation (Figure 3d).
Sensitization to TRAIL-induced cell death by 5FU has previously been described to involve the deregulation of c-FLIP. ${ }^{4,16}$ We, therefore, analyzed c-FLIP expression after

a

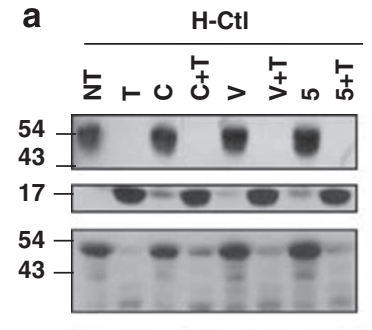

H-TRAIL-R4

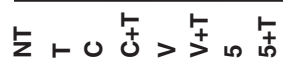
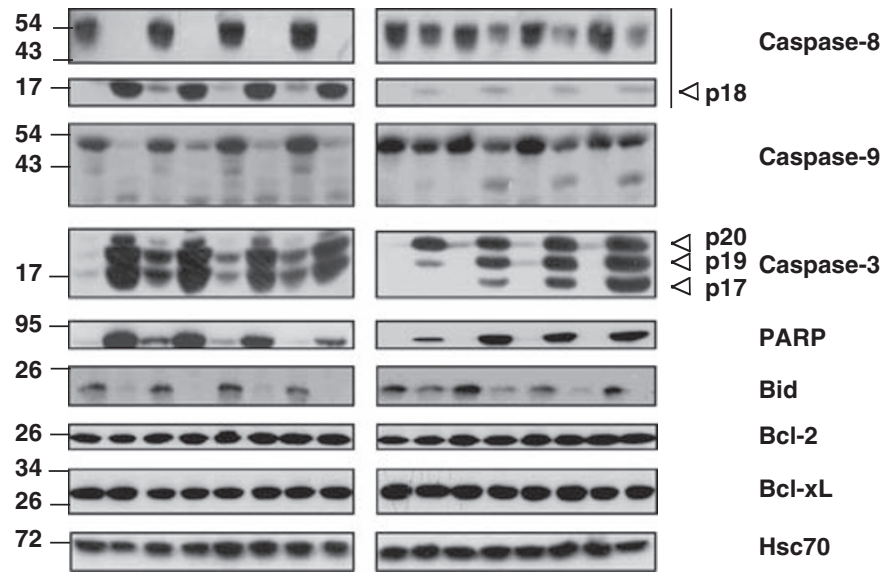

$\triangleleft$ p20

19 Caspase-3

C

b

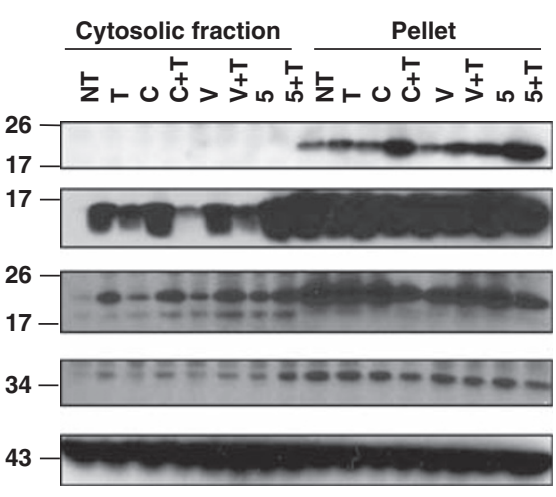

d
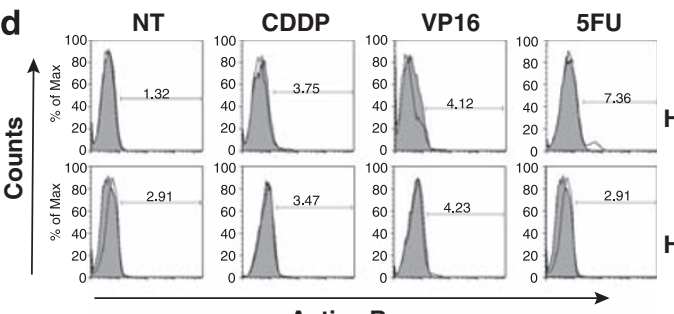

Active Bax

Trail

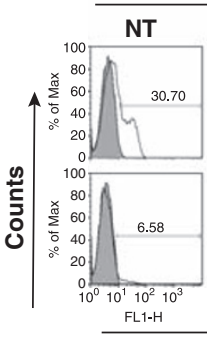

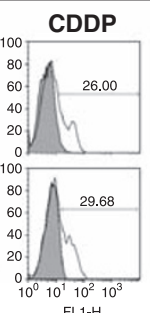

PARP

Bid

Bcl-2

Bcl-xL

Hsc70

H-TRAIL-R4

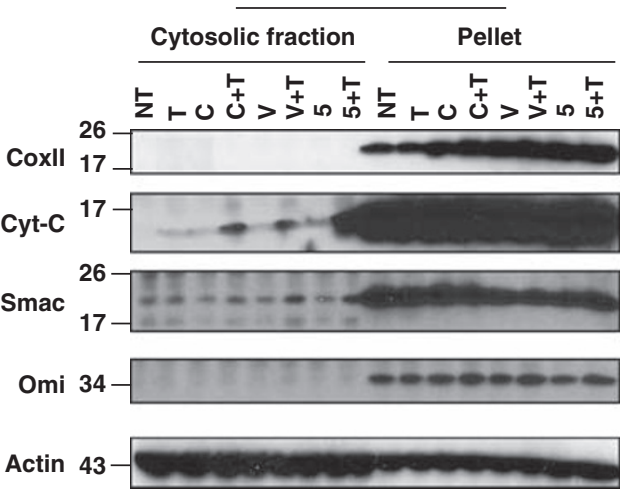

e

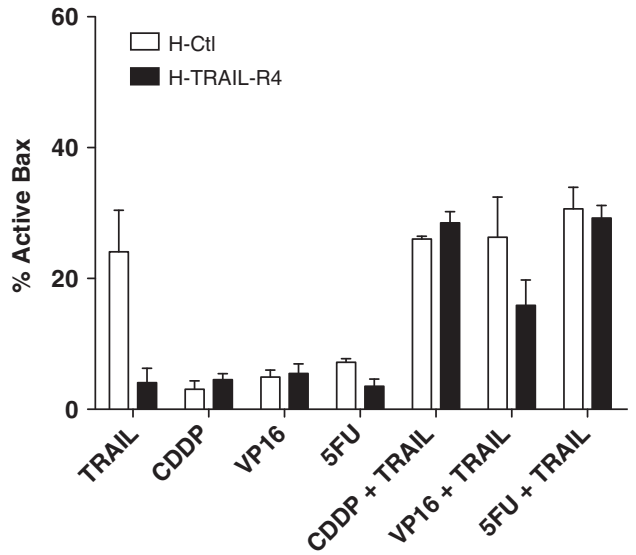

Figure 2 Continued. (For caption refer next page) 
chemotherapy at the time when the cells were exposed to TRAIL stimulation. Contrary to our expectations, we found that 5 FU poorly induced c-FLIP deregulation in our settings (Figure 3e), but that CDDP and VP16 induced c-FLIP upregulation in these cells (Figure $3 e$ ). Consistent with these findings, expression of c-FLIP abrogated sensitization to TRAIL after 5FU treatment, irrespective of TRAIL-R4 or Bax expression in HCT116 cells (Figure $3 f$ ), indicating that the mere upregulation of c-FLIP is probably sufficient to impair the synergy irrespective of the mitochondria. In agreement with this finding, the caspase-9 inhibitor z-LEHD-fmk failed to protect TRAIL-R4-expressing cells from TRAIL-induced cell death after chemotherapy, while the pan-caspase inhibitor z-VAD-fmk completely abrogated the synergy (Supplementary Figure S3).

\section{Chemotherapeutic drugs enhance caspase-8 recruitment and activation within the TRAIL DISC. To} determine the contribution of TRAIL DISC formation and caspase-8 activation in the synergy, c-FLIP was coexpressed in H-TRAIL-R4 cells and cells were stimulated with TRAIL after chemotherapy. Like TRAIL-R4, expression of c-FLIP (Figure $3 \mathrm{~g}$ ) reduced cell sensitivity to TRAIL, but alone failed to block apoptosis induced by TRAIL upon chemotherapy (Figure 3h). However, combined expression of TRAIL-R4 and C-FLIP severely impaired TRAIL-induced apoptosis by chemotherapeutic drugs, indicating that activation of caspase-8 per se has a prominent role in the synergy (Figure $3 \mathrm{~h}$ ). In agreement with these findings, DISC analysis in cells subjected to chemotherapy and TRAIL treatments revealed that chemotherapeutic drugs enhanced caspase-8 recruitment and activation within the TRAIL DISC in HeLa control cells (Figure 4a) but, probably more importantly, also in HeLa expressing TRAIL-R4 (Figure 4b) and VAL cells (Figure 4c), which express TRAIL-R4 endogenously. Altogether, these results clearly demonstrate that TRAIL-R4 inhibits TRAIL-induced cell death, and that chemotherapy can restore tumor cell sensitivity to apoptosis, mainly through the restoration of caspase-8 recruitment and activation within the DISC. TRAIL-R4 inhibits TRAIL-induced cell death but not chemo-
therapy-induced sensitization to TRAIL in vivo. Ability of
TRAIL-R4 to prevent TRAIL-induced tumor regression,
combined or not with chemotherapy, was next evaluated in
nude mice using xenografts of HCT116 cells expressing
TRAIL-R4. Mice were implanted, in both flanks, with
HCT116-Ctl cells (right flank) and HCT116-TRAIL-R4 (left flank). When the tumor volume reached $20 \mathrm{~mm}^{3}$, mice were treated with phosphate-buffered saline (PBS), CDDP, recombinant TRAIL or treated sequentially with CDDP and TRAIL as described in the Materials and Methods section. Compared with PBS-treated mice, HCT116-Ctl tumor growth was inhibited in mice receiving injections of TRAIL, CDDP and by the combined treatment (Figure 5a). However, TRAIL, and to a lesser extent CDDP, failed to induce tumor regression in TRAIL-R4-expressing cells (Figure 5b), but combined treatments induced a marked inhibition of the tumor growth of HCT116 cells expressing TRAIL-R4 (Figure 5b), with statistically significant $P$-values $<0.001$ as compared with PBS-treated mice. These results demonstrate that TRAIL-R4 efficiently inhibits TRAIL-induced cell death not only in vitro, but also in vivo. However, chemotherapeutic drugs, including CDDP, can overcome TRAIL-R4 mediated resistance, highlighting the potential therapeutic value of these combined therapies for cancer.

\section{Discussion}

TRAIL-based combinatorial therapies are emerging paradigms for cancer treatment as synergistic activation of TRAIL-induced apoptosis by chemotherapeutic drugs generally affords to overcome tumor cell resistance, whereas monotherapies are most of the time poorly successful. Preclinical studies and clinical trials are giving promising results, supporting the potential of these combining approaches. ${ }^{17,18}$

Cell surface expression of TRAIL agonistic receptors is the first requirement in order to trigger the TRAIL apoptotic machinery but, to date, the expression of TRAIL receptors in primary tumors remains poorly studied and the anti-apoptotic function of TRAIL-R4 remains controversial. It was found, however, in a few studies that primary lymphomas could express functional TRAIL antagonistic receptors at the cell surface. $^{10}$ In solid tumors, analysis of TRAIL receptor expression was often performed by immunohistochemistry, and although this method does not provide the information whether the receptors are expressed at the cell surface, these studies indicate that the extent of expression of the antagonistic receptors TRAIL-R3 and TRAIL-R4 is probably underestimated..$^{9,19-21}$

Engagement of apoptosis upon TRAIL stimulation in a given tissue type, primary tumor or cell line, relies on the contribution of multiple players, including proapoptotic and prosurvival factors, which ultimately determine cell fate. It has

Figure 2 Chemotherapeutic drugs activate the mitochondrial apoptotic pathway. (a) Western blot analysis of caspase-8, caspase-9, and caspase-3, PARP, Bid, Bcl-2, $\mathrm{Bcl}-\mathrm{xL}$ and hsc70 in control HeLa cells (H-Ctl) or cells expressing TRAIL-R4 (H-TRAIL-R4) after stimulation with His-TRAIL (T) and/or chemotherapeutic pretreatments with cisplatin (C), etoposide (V) or 5FU (5). White arrows indicate cleavage fragments. Molecular size markers are shown on the left in $\mathrm{kDa}$. These results are representative of at least three independent experiments. (b) and (c) A digitonin-based permeabilisation experiment followed by western blot analysis of the different fractions (cytosolic or pellet) was performed to analyze the release of cytochrome $c, S m a c$ and Omi from the mitochondria. Coxll antibody was used as a control for efficient subcellular fractionation and the actin was probed for normalization. Control HeLa cells and H-TRAIL-R4 cells were treated as previously with cisplatin (C), etoposide (V) or 5-fluorouracil (5) plus or minus His-TRAIL (T). Molecular size markers are shown on the left in kDa. (d) Control HeLa cells and H-TRAIL-R4 cells were pre-treated as above with cisplatin (CDDP), etoposide (VP16) or 5-fluorouracil (5FU) then subsequently stimulated or not with His-TRAIL (TRAIL), as in Figure 1. After treatment, cells were permeabilized and stained with an antibody recognizing active Bax and analyzed by flow cytometry. (e) The percentage of cells containing active Bax was determined by FACS in control HeLa cells (H-Ctl, white bars) or TRAIL-R4-expressing cells (H-TRAIL-R4, black bars). These results are representative of at least three independent experiments. Mean \%Active Bax values and S.D. are shown (mean \pm S.D.). (For figure refer previous page) 


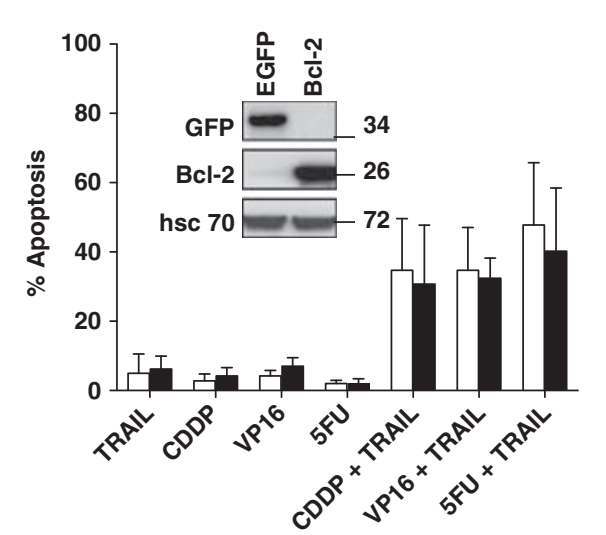

b $\begin{aligned} & 100 \\ & 80\end{aligned}$

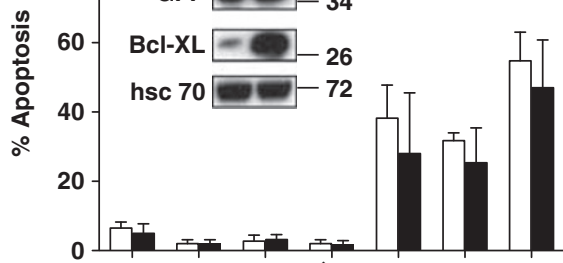

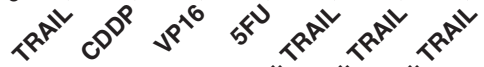

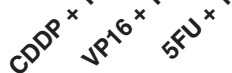

d $\square$ HCT116 wt Ctl

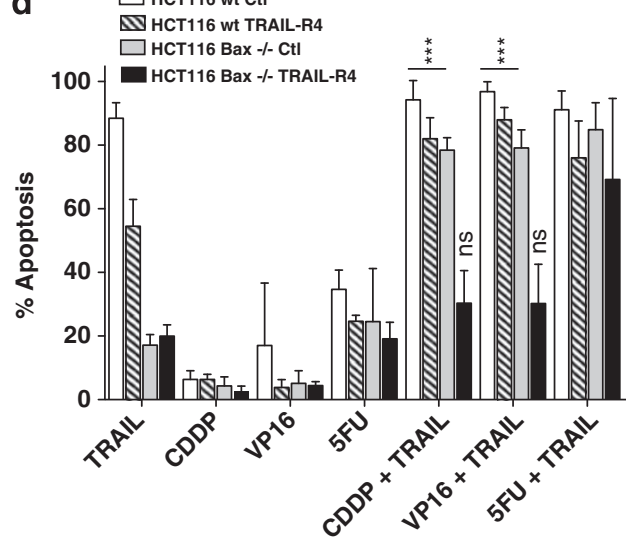

e
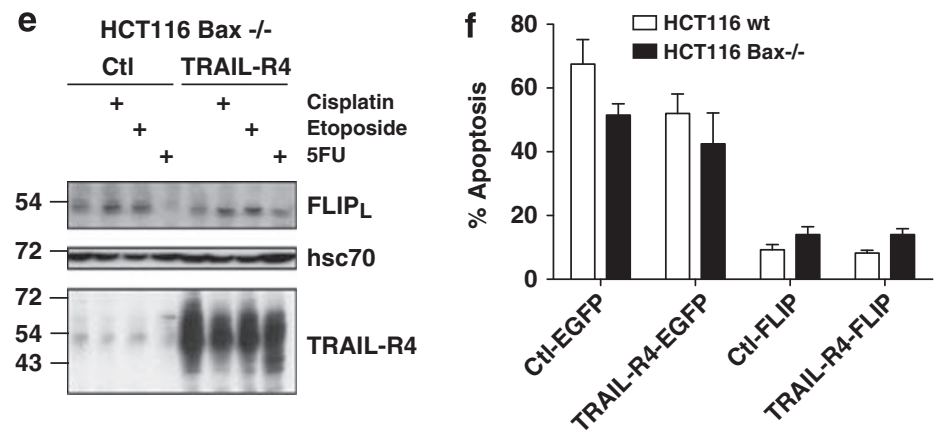

TRAIL-R4
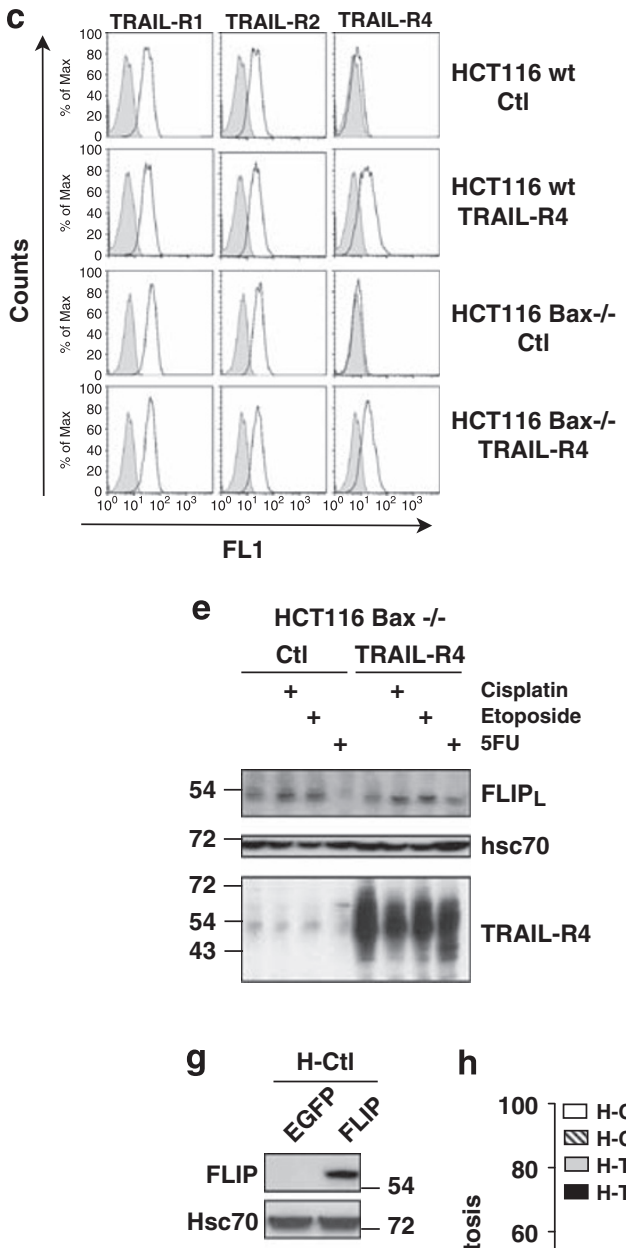

h

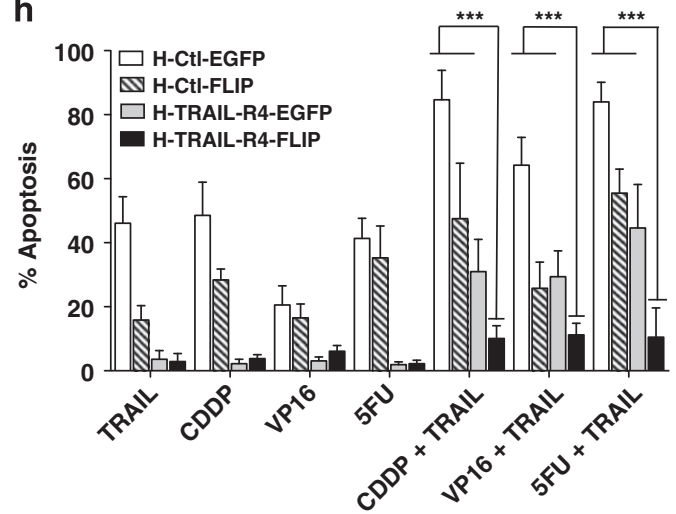

Figure 3 Continued. (For caption refer next page) 
recently been demonstrated that naturally occurring differences in the levels or states of proteins regulating TRAIL signaling are the primary causes of cell-to-cell variability. ${ }^{22}$ The large variety of cellular changes in protein levels or status induced by chemotherapeutic drugs may explain why these drugs, restore TRAIL sensitivity in resistant cells, albeit targeting different signaling pathways. Sensitization to TRAIL by chemotherapeutic drugs, has been attributed to multiple molecular mechanisms including the upregulation of TRAIL$\mathrm{R} 2,{ }^{23}$ activation of the mitochondrial pathway ${ }^{24,25}$ inhibition of c-FLIP expression ${ }^{26}$ or enhanced caspase- 8 recruitment to the TRAIL DISC. ${ }^{4,5}$

We demonstrate here that chemotherapy overcomes TRAIL resistance induced by TRAIL-R4 at the level of the DISC, and provide strong evidence that the mitochondrial pathway is dispensable for the restoration of TRAIL sensitivity by chemotherapeutic drugs (Figure 6). Chemotherapeutic drugs afforded sensitization to TRAIL of aggressive B-cell follicular lymphomas such as VAL cells, despite endogenous expression of functional TRAIL-R4 and Bcl-2. Likewise, these compounds restored TRAIL sensitivity of epithelial-derived tumor cell lines harboring either a deficiency for Bax expression, or engineered to express $\mathrm{Bcl}-2$ or $\mathrm{Bcl}-\mathrm{x}_{\mathrm{L}}$, irrespective of TRAIL-R4 expression levels. Bax deficiency however, may be detrimental to some chemotherapeutic drugs in cells that express TRAIL-R4 and low but significant levels of c-FLIP. Accordingly, restoration of TRAIL sensitivity in HCT116 Bax-deficient cells expressing TRAIL-R4 was only observed with 5FU, but not CDDP or VP16 because of their ability to induce c-FLIP expression. These results could explain some discrepancies regarding the lack of correlation regarding TRAIL-R4 expression and cell sensitivity to TRAILinduced cell death. In particular, C-FLIP expression levels have scarcely been taken into consideration in these studies.

Our results demonstrate that TRAIL-R4 can inhibit TRAILinduced cell death both in vitro and in vivo, and cooperate with C-FLIP to inhibit chemotherapy-mediated sensitization to TRAIL-induced apoptosis (Figure 6). These findings not only have important implications for the understanding of the molecular mechanisms involved in the regulation of TRAIL signaling, but also for therapeutic approaches aiming at utilizing recombinant TRAIL to cure patients suffering from cancer.

The physiological function and relevance of TRAIL-R4 is still unclear. Our study is probably the first demonstration that TRAIL-R4 can confer TRAIL resistance in vivo, as we demonstrate that ectopic expression of this receptor in the colon carcinoma cell line HCT116 efficiently impairs TRAILinduced tumor killing in nude mice. At the physiological level, TRAIL-R4 could protect cells selectively from TRAIL-induced cell death. Noteworthy, it has been demonstrated that NK and CD8 $+\mathrm{T}$ cells are induced to express TRAIL, TRAIL-R2, TRAIL-R4 and c-FLIP upon activation. ${ }^{27}$ Despite high expression levels of TRAIL, these cells are resistant to TRAIL, but selective inhibition of c-FLIP expression induced TRAIL sensitivity. ${ }^{27}$ It should be noted, however, that selective TRAIL-R4 downregulation was not assessed in this study, therefore, it is conceivable that TRAIL-R4 may also have a role in protecting these cells from TRAIL-induced cell death. Although the function of TRAIL-R4 remains to be determined in a physiological context, our results indicate that this receptor in pathological conditions, such as overexpression in primary tumor cells, could represent a problem in oncology. Our results clearly support the inhibitory potential of TRAIL-R4 and, in agreement with previous studies, ${ }^{4,5}$ sustain the demonstration that chemotherapy sensitize tumor cells to TRAIL mainly through the regulation of caspase-8 activation at the DISC level.

The molecular mechanisms leading to the restoration of caspase-8 recruitment and enhancement of caspase-8 activation within the TRAIL DISC after chemotherapy remains an open question. Some reports indicate that chemotherapeutic drugs could enhance TRAIL receptor clustering at the cell surface, through ceramide production and receptor partitioning into lipid rafts. ${ }^{28,29}$ Work is currently in progress to address this question in our laboratory.

Figure 3 The mitochondrial pathway is dispensable for the synergy in TRAIL-R4 expressing HeLa cells. (a) H-TRAIL-R4 cells were infected using the pBabe-blasticidin retroviral vector encoding EGFP or Bcl-2. The expression of the different transgenes was checked by western blot using an anti-Bcl-2 or anti-GFP antibody. Hsc70 was used as a loading control. Molecular size markers are shown on the right in kDa. TRAIL-R4 HeLa cells overexpressing EGFP (EGFP, in white) or Bcl-2 (Bcl-2, in black) were pre-treated with the chemotherapeutic drugs as described in Figure 1 and sequentially treated with His-TRAlL $(500 \mathrm{ng} / \mathrm{ml}$ for $6 \mathrm{~h})$. Apoptosis was quantified by Hoechst staining. (b) H-TRAIL-R4 cells were infected with PMIG empty vector (EGFP) or pMIG-Bcl-xL and analyzed by western blot. Molecular size markers are shown on the right in kDa. Sensitivity to apoptosis induced by His-TRAIL, chemotherapy or sequential treatments (H-TRAIL-R4-EGFP, white; H-TRAIL-R4-Bcl-xL, black) was assessed by Hoechst staining. (c) HCT116 parental (HCT116 wt) and HCT116 Bax-/ - cells were infected with an empty pMSCV-vector (HCT116 wt Ctl and HCT116 Bax-/- Ctl) or with pMSCVvector encoding TRAIL-R4 (HCT116 wt TRAIL-R4 and HCT116 Bax-/- TRAIL-R4). Expression of TRAIL receptors was analyzed by flow cytometry. (d) Apoptosis induced by His-TRAIL $(500 \mathrm{ng} / \mathrm{ml}, 6 \mathrm{~h}$ ) after chemotherapeutic treatment was measured by Hoechst staining in HCT116 parental Bax wt Ctl (white), HCT116 wt overexpressing TRAlLR4 (HCT116 wt TRAIL-R4, dashed), HCT116 Bax-/- Ctl (gray) and HCT116 Bax-/- overexpressing TRAIL-R4 cells (HCT116 Bax-/- TRAIL-R4, black). These results are representative of three independent experiments performed in triplicate. Mean percentage of apoptotic cells values and S.D. are shown (mean \pm S.D.). Differences between selected groups were compared by non-parametric analysis of variance (ANOVA) with Bonferroni post hoc multiple comparison test, ${ }^{* \star \star} P<0.001$, compared with TRAIL stimulation alone in HCT116 Bax-deficient or HCT116 Bax-deficient expressing TRAIL-R4 cells, ns (not statistically significant). (e) Cells were stimulated as above for $3 \mathrm{~h}$ with treatments CDDP or VP16 or $72 \mathrm{~h}$ with $5 \mathrm{FU}$, and c-FLIP or TRAIL-R4 expression was analyzed by western blotting $48 \mathrm{~h}$ or immediately after stimulation, respectively. Molecular size markers are shown on the left in kDa. (f) HCT116 Bax wt and Bax-/ - control (Ctl) or TRAIL-R4 (TRAIL-R4) were infected with pMIG-FLIP (FLIP) or an empty vector (EGFP), and sorted by flow cytometry based on GFP positivity. Sensitivity to TRAIL-induced apoptosis after a $72 \mathrm{~h}$ pre-treatment with $5 F U$ was measured by Hoechst staining $6 \mathrm{~h}$ after His-TRAIL $(500 \mathrm{ng} / \mathrm{ml})$ treatment. (g) HeLa control $(\mathrm{H}-\mathrm{Ctl})$ and HeLa overexpressing TRAIL-R4 (H-TRAIL-R4) were infected with pBabe-EGFP or pBabeFLIP. Expression of the different transgenes was checked by western blot. (h) Cells overexpressing EGFP (H-Ctl-GFP in white bars and H-TRAIL-R4-GFP in gray bars) or FLIP (H-Ctl-FLIP dashed bars and H-TRAIL-R4-FLIP in black bars) were stimulated with the chemotherapeutic agents, as described previously, and sequentially treated with His-TRAIL $(500 \mathrm{ng} / \mathrm{ml})$ for $6 \mathrm{~h}$. Apoptotic cells were counted after Hoechst staining. These results are representative of at least three independent experiments. Mean percentage of apoptotic cells and S.D. are shown (mean \pm S.D.). Differences between selected groups were compared by non-parametric analysis of variance (ANOVA) with Bonferroni post hoc multiple comparison test. ${ }^{* * *} \mathrm{P}<0.001$, H-TRAIL-R4-FLIP compared with H-Ctl-Mock, H-Ctl-FLIP or H-TRAIL-R4-Mock. (For figure refer previous page) 
a

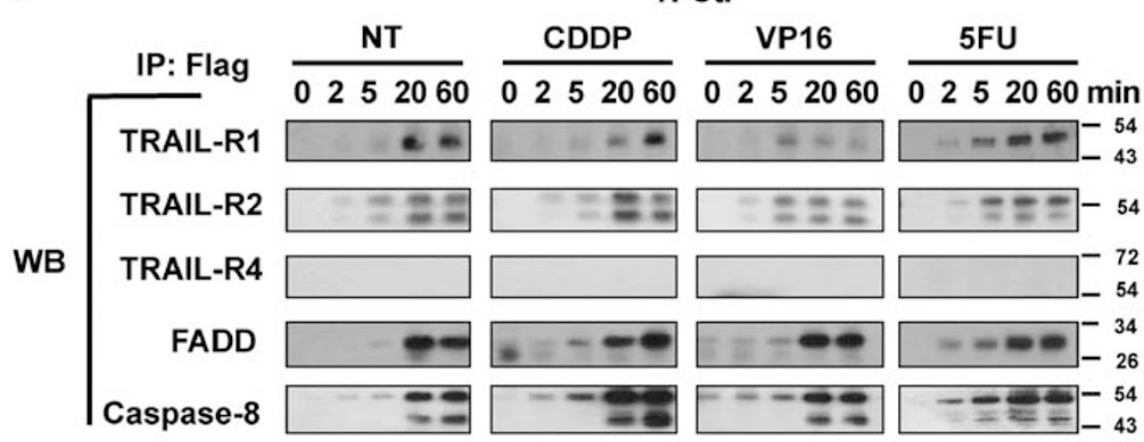

b

H-TRAIL-R4

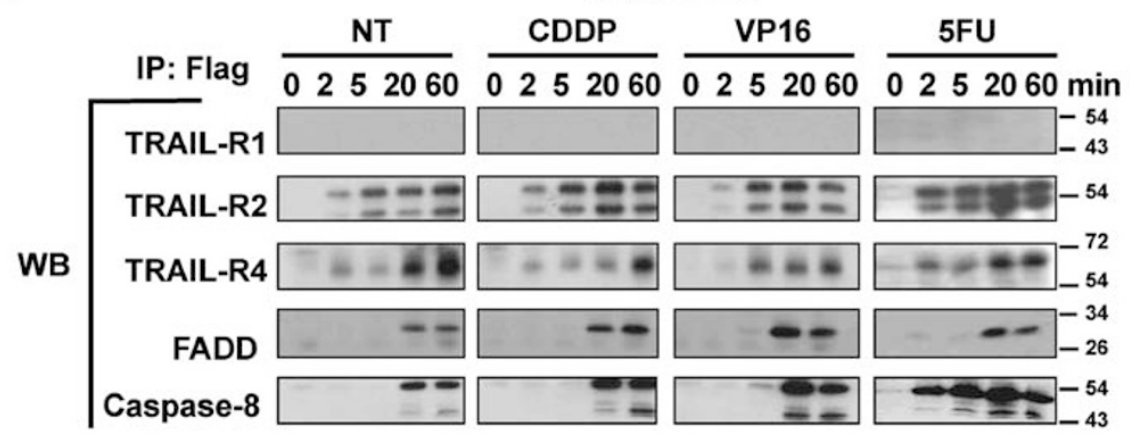

C

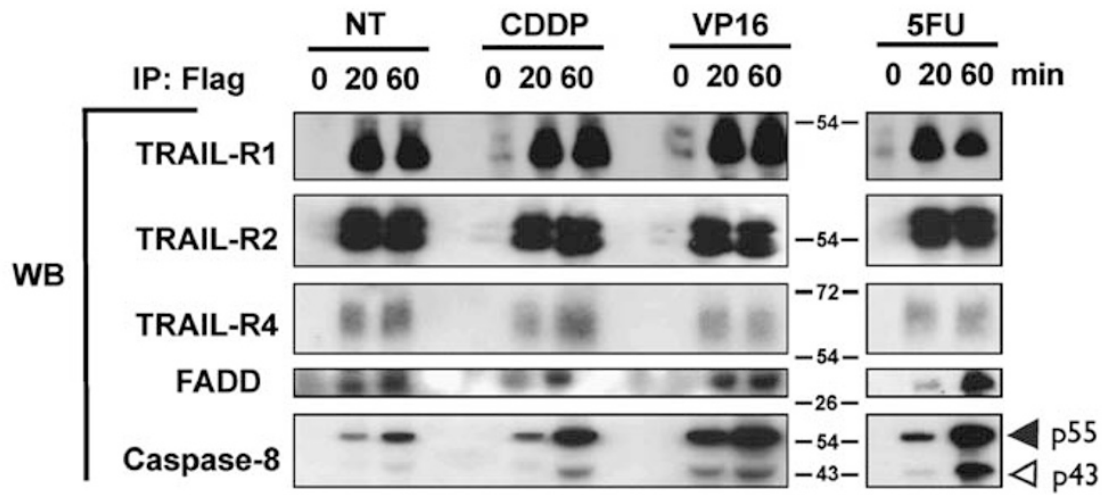

Figure 4 Chemotherapeutic drugs restore TRAIL sensitivity at the DISC level. (a) control HeLa cells (H-Ctl), (b) TRAIL-R4 expressing HeLa cells (H-TRAIL-R4) or (c) VAL cells were pre-treated with CDDP, VP16 or 5FU or left untreated as described in Figure 1, then stimulated with TRAIL for the indicated time. TRAIL DISC was immunoprecipitated (see Materials and Methods section) and analyzed by western blot. Molecular size markers are shown on the right in $\mathrm{kDa}$

Remarkably, like c-FLIP, ${ }^{30,31}$ ectopic expression of TRAILR4 induced cross-resistance to some chemotherapeutic drugs in vitro and in vivo. How TRAIL-R4 impairs chemotherapy-induced apoptosis remains to be determined. Some reports point to the observation that forced aggregation of some death receptors of the TNF family including Fas, or downstream effectors like Bid, may contribute to genotoxic drug-induced apoptosis in a ligand-independent manner. ${ }^{31-33}$ Combined expression of TRAIL-R4 and c-FLIP may, therefore, not only impair TRAIL-induced cell death after chemotherapy, but may also alter chemotherapy itself. In line with this hypothesis, it has been demonstrated that c-FLIP and TRAIL-R4 are overexpressed in a growing number of primary tumors and that their expression levels has recently been defined as a poor prognostic marker in colorectal ${ }^{34}$ and prostate cancer patients. $^{35}$

Altogether our results clearly demonstrate that TRAIL-R4 is a negative regulator of TRAIL whose inhibitory function can be overcome using chemotherapy to restore TRAIL-induced cell death. However, we also demonstrate that TRAIL-R4 cooperates with C-FLIP to inhibit TRAIL-induced apoptosis after chemotherapy. Their ability to cooperate and to efficiently inhibit TRAIL-induced apoptosis needs to be taken into consideration both in vitro and in future clinical trials to assess the efficacy of combinatorial treatments associating recombinant TRAIL with chemotherapy. It is anticipated that patients expressing both TRAIL-R4 and c-FLIP may respond better to alternative therapeutic approaches, including 

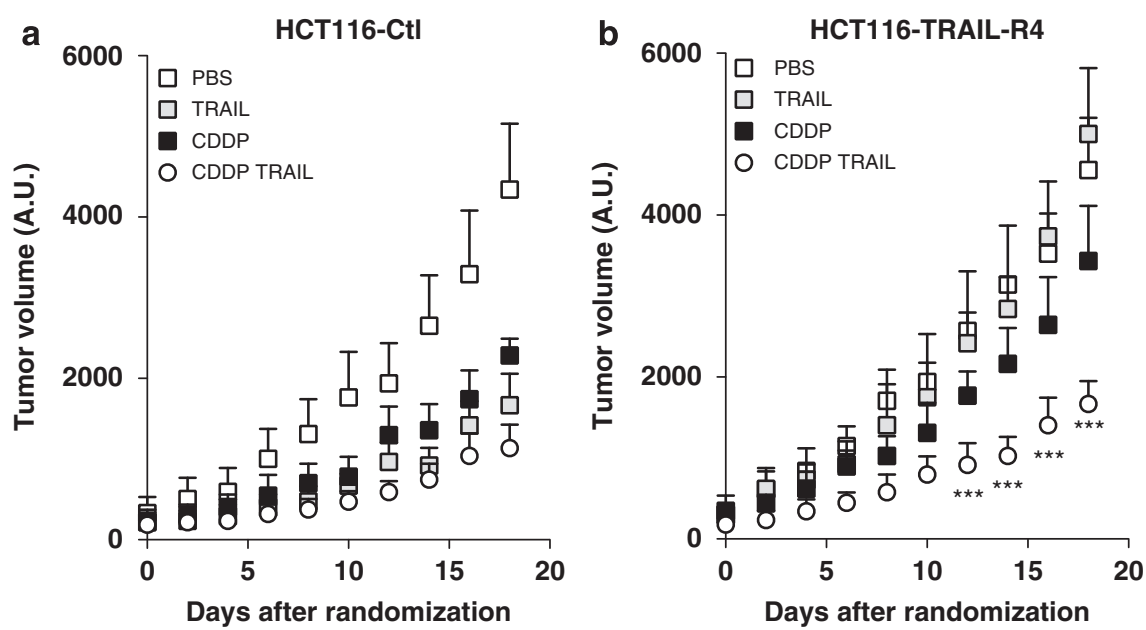

Figure 5 Chemotherapeutic drugs restore TRAIL sensitivity in vivo. (a) and (b), HCT116-Ctl or HCT116-TRAIL-R4 cells were implanted into NMRI nu/nu mice and allowed to reach $20 \mathrm{~mm}^{3}$. After randomization (day 0), mice were either injected with PBS (white squares), His-TRAlL alone at $8 \mathrm{mg} / \mathrm{kg}$ (gray squares), CDDP at $4 \mathrm{mg} / \mathrm{kg}$ (black squares) or sequentially with CDDP and 2 days later with His-TRAlL $8 \mathrm{mg} / \mathrm{kg}$ (white circle). Mice were subjected to two treatments spaced within 2 days. Tumors were measured every 2 days using a caliper. The combination was found statistically different from single treatments ( $\left.{ }^{\star \star *} P<0.001\right)$ at days $14,16,18$ and 20 as analyzed by ANOVA, two-sided. These results represent mean tumor volume in arbitrary units \pm S.D. of 9 to 10 mice per group from three independent experiments

non-conventional chemotherapeutic drugs, TRAIL derivatives, targeting specifically TRAIL-R2, or to strategies aiming at inhibiting c-FLIP expression or blocking TRAIL-R4.

\begin{abstract}
Materials and Methods
Ligand production and antibodies. Flag-tagged recombinant soluble human TRAIL, his-tagged TRAIL and FasL were produced and used as described previously. ${ }^{36}$ Anti-Flag (M2) and staurosporin were from Sigma-Aldrich (Lyon, France). For western blot analysis, anti-TRAIL-R1, anti-TRAIL-R2, anti-TRAIL-R3 and anti-TRAIL-R4 antibodies were purchased from Chemicon (Millipore, Molsheim, France), anti-FADD was obtained from Transduction Laboratories (BD biosciences, Le Pont de Claix, France), anti-caspase-8 and anti-caspase-10 were from Medical \& Biological Laboratories (Clinisciences, Montrouge, France). Antibodies against active cleaved fragment of caspase-3, and PARP were from Cell Signaling (Millipore), anti-GFP, Bcl-2, cytochrome c, Bax (N-20) and HSC-70 were from Santa Cruz Biotechnology (Tebu-bio, Le Perray en Yvelines, France) and anti-caspase-9 was from Upstate (Millipore). Anti-Bid, anti-Bcl-xL and anti-FLIP (NF6) antibodies were purchased from BD Pharmingen, Transduction Lab (BD Biosciences), Calbiochem (VWR, Fontenay-sous-Bois, France) and Alexis (Coger, Paris, France), respectively. Anti-Coxll, anti-Smac/DIABLO and anti-Omi/HtrA2 were from Molecular probes (Invitrogen, Cergy Pontoise, France), Proscience (Coger, Paris, France) and R\&D systems (Lille, France), respectively. For flow cytometry experiments, the anti-TRAIL-R1, anti-TRAIL-R2, anti-TRAIL-R3 and anti-TRAIL-R4 (clones wB-K32, B-L27, wB-B44 and wB-P30 respectively), were kindly provided by Diaclone (Besançon, France). The secondary antibody was an Alexa-488 coupledgoat anti-mouse from Molecular Probes (Invitrogen). The pan-caspase inhibitor (z-VAD-fmk) and caspase-9 inhibitor (z-LEHD-fmk) were purchased from Alexis.
\end{abstract}

Cell culture. The HeLa (human cervix carcinoma) and SW480 (human colon adenocarcinoma) cell lines were cultured with high-glucose Dulbecco's modified Eagle's medium medium (Lonza, Levallois-Perret, France) supplemented with 10\% fetal bovine serum (Lonza) and penicillin/streptomycin (100 mg/ml of each). The Jurkat (human T lymphoma) cells, VAL (human B lymphoma) and HCT116 human colon adenocarcinoma cell lines were cultured in RPMI 1640 medium (Lonza) containing $10 \%$ fetal bovine serum and penicillin/streptomycin. All these cell lines were grown in $5 \% \mathrm{CO}_{2}$ at $37^{\circ} \mathrm{C}$. $\mathrm{HCT} 116 \mathrm{Bax}+/-$ or $\mathrm{Bax}-1-$ are kind gifts of Dr. Bert Vogelstein (Johns Hopkins University School of Medicine, Baltimore, MD, USA).
Retrovirus production and cell transduction. The retroviral vector pMSCV-puro for TRAIL-R4 expression and generation of viruses has been previously described. ${ }^{37}$ Cells were transduced for $16 \mathrm{~h}$ with viral supernatants containing polybrene $(8 \mathrm{mg} / \mathrm{ml})$, washed in PBS, and cultured in complete medium containing puromycin $(2.5 \mathrm{mg} / \mathrm{ml})$. EGFP, FLIPL and $\mathrm{Bcl}-2$ were cloned into pBabe-Blasticidin. Transduced cells were then selected with blasticidin $(2.5 \mu \mathrm{g} / \mathrm{ml})$. pMIG-Bcl-xL expression vector ${ }^{38}$ was purchased from Addgene (plasmid 8790, Cambridge, MA, USA). pMIG-FLIP was obtained as previously described. ${ }^{14}$ After transduction, cells were sorted using a cell sorter Coulter Epics Elite ESP (Beckman-Coulter-France, Villepinte, France).

Treatments with chemotherapy and TRAIL. For sequential treatments, cells were treated for $3 \mathrm{~h}$ with CDDP $(20 \mu \mathrm{M})$ or VP16 $(10 \mu \mathrm{M})$ in serum-free medium and then washed. Cells were cultured for $48 \mathrm{~h}$ in complete medium before being treated for $6 \mathrm{~h}$ with His-TRAIL $(500 \mathrm{ng} / \mathrm{ml})$. 5FU was added in complete medium $72 \mathrm{~h}$ before TRAIL treatments and the Hoechst analysis.

Hoechst analysis. Apoptosis was assessed by Hoechst staining and determination of the percentage of condensed and fragmented nuclei from at least 300 cells per conditions. Experiments were repeated at least three times.

Bcl-2 and TRAIL-R4 gene silencing by siRNA. TRAIL-R4 SiRNA \#1 (5'-UCCUUAAGUUCGUCGUCUU-3'), TRAIL-R4 SIRNA \#2 (5'-UCACUACCUUAU CAUCAUA-3') and TRAIL-R4 siRNA \#3 (5'-GGGUGUGGAUUACACCAUU- $3^{\prime}$ ) were purchased from Eurogentec (Angers, France). Bcl-2 siRNA was purchased from Invitrogen. Cells were transfected with a scramble, Bcl-2 or TRAlL-R4 targeting siRNAs using Amaxa cell line nucleofector kit V (Lonza) with transfection program N016. $48 \mathrm{~h}$ after transfection, Bcl-2 and TRAIL-R4 expression were monitored either by western blotting or by flow cytometry, and sensitivity to TRAIL was assessed by Hoechst.

Bax activation by flow cytometry analysis. Cells, treated or untreated with His-TRAIL and/or chemotherapy were fixed with 4\% PFA, permeabilized (PBS, BSA $1 \%$ and saponin $0.1 \%$ ) for $10 \mathrm{~min}$ at room temperature and stained with an anti-Bax antibody which recognizes the active N-terminal form of Bax (clone 6A7, Tebu-bio). In all, 10000 events were analyzed using a LSR2 flow cytometer (BD Biosciences).

Digitonin permeabilization. After treatment, cells were washed in $\mathrm{PBS}$ and lysed in buffer containing $75 \mathrm{mM} \mathrm{KCl}, 1 \mathrm{mM} \mathrm{NaH}_{2} \mathrm{PO}_{4}, 8 \mathrm{mM} \mathrm{Na}_{2} \mathrm{HPO}_{4}$ and $250 \mathrm{mM}$ sucrose containing $400 \mu \mathrm{g} / \mathrm{ml}$ digitonin. Cells were kept on ice to obtain $90-95 \%$ of 


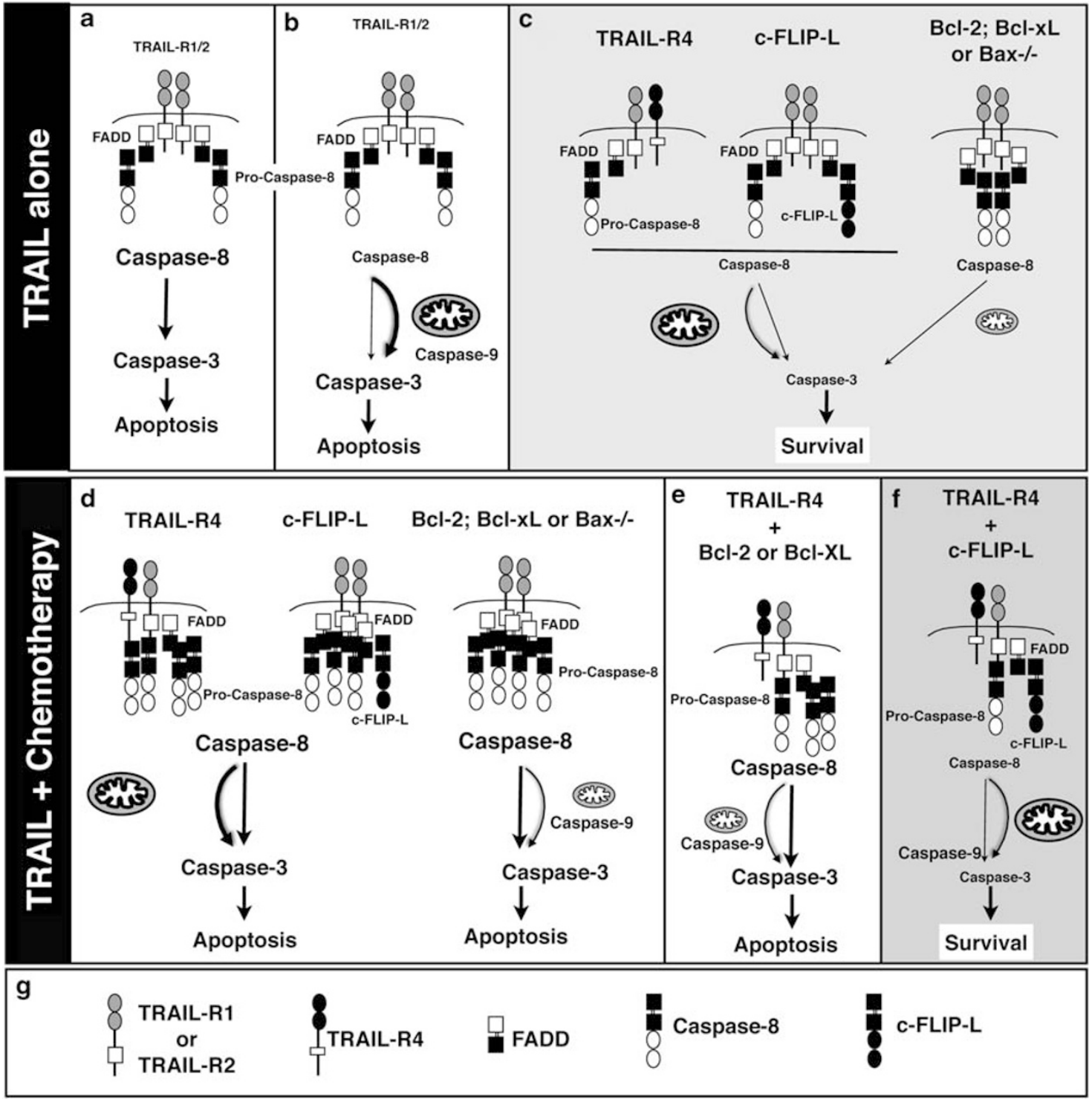

Figure 6 Proposed model of TRAIL-induced cell death regulation. (a) Direct activation of caspase-8 by TRAIL in type I cells. (b) A mitochondrial amplification loop of caspase activation in type II cells is required because of reduced caspase-8 activation upon TRAIL engagement. (c) Overexpression of TRAIL-R4, FLIP-L or mitochondrial block, protects type II cells from TRAIL-induced cell death. TRAIL-R4 and c-FLIP-L limit caspase-8 activation within the TRAIL DISC, which impairs mitochondrial activation, leading to low caspase-3 activation and survival. Mitochondrial block in type II cells, induced by Bcl-2 or Bcl-xL overexpression or Bax-deficiency inhibit amplification of the signal. Caspase-8 is activated but much less efficiently than in type I cells, leading to low caspase-3 activation and survival. (d) Chemotherapeutic drugs restore TRAIL sensitivity mainly through enhanced capase-8 recruitment to and activation at the DISC. Thus, the threshold of active caspase-8 required to induce direct caspase-3 activation can be reached and cells undergo apoptosis, overcoming TRAIL-R4- and c-FLIP-mediated inhibition of caspase-8, but also inhibition induced by Bcl-2 or BCl- $x_{L}$ overexpression or Bax-deficiency. (e) Inhibition of the mitochondrial pathway by Bcl-2 or Bcl-xL overexpression in TRAIL-R4-expressing cells fails to compromise chemotherapy-induced sensitization to TRAIL. (f) Forced inhibition of caspase-8 activation in TRAIL-R4 and c-FLIP-L-expressing cells abrogates apoptosis induced by TRAIL after chemotherapy. (g) Schematic representation of TRAIL receptors, FADD, c-FLIP and caspase-8

trypan blue-permeabilized cells. After 5 min at $16000 \times g$, supernatants were collected as the cytosolic fraction. Pellets were then lysed in buffer containing $1 \%$ Triton-X100. After centrifugation for $20 \mathrm{~min}$ at $16000 \times \mathrm{g}$, supernatants were collected.

Immunoprecipitations. For DISC analysis, $10^{8}$ cells in $1 \mathrm{ml}$ of medium were stimulated with $5 \mu \mathrm{g}$ Flag-TRAIL cross-linked with $10 \mu \mathrm{g}$ of M2 antibody for the indicated times at $37^{\circ} \mathrm{C}$. Cells were then washed with cold phosphate saline buffer, lysed in $1 \mathrm{ml}$ of lysis buffer containing 1\% NP40, $20 \mathrm{mM}$ Tris-HCl pH 7.5, $150 \mathrm{mM}$ $\mathrm{NaCl}$ and $10 \%$ glycerol. Lysates were pre-cleared with Sepharose 6B (SigmaAldrich), and immunoprecipitated overnight at $4^{\circ} \mathrm{C}$ with $\mathrm{G}$-protein Sepharose beads (Amersham Biosciences, Les Ullis, France). Beads were then washed four times with the respective detergent, and immunoprecipitates were eluted in lysis buffer (Tris-HCl $63 \mathrm{mM}$, SDS $2 \%$, phenol red $0.03 \%$, glycerol $10 \%$ and DTT $100 \mathrm{mM}$ of pH $6.8)$, boiled for $5 \mathrm{~min}$ and processed for immunobloting.

Western blotting. Immunoprecipitates or cell lysates were resolved by SDS-PAGE and transferred to nitrocellulose membranes. Nonspecific binding sites were blocked by incubation in PBS containing $0.05 \%$ of Tween 20 and $5 \%$ of milk powder. Immunoblots were then incubated with specific primary antibody followed by HRP-conjugated secondary antibody and were developed by the enhanced chemiluminescence method according to the manufacturer's protocol (Pierce, Rockford, IL, USA) 
In vivo evaluation of the combination of CDDP and TRAIL. 5-weekold athymic female mice (NMRI nu/nu) were obtained from Janvier (Le Genest Saint-Isle, France). This protocol was approved by the local Animal Ethical committee (Université de Bourgogne, Dijon, France). Mice were subcutaneously xenografted with $4 \times 10^{6} \mathrm{HCT} 116$-Ctl cells in the right flank and $4 \times 10^{6} \mathrm{HCT} 116$ TRAIL-R4 in the left flank. Mice were weighed and tumor volume was evaluated every 2 days by caliper measurement using the following formula: $(I \times I \times L) / 2$, with I the lower and $L$ the higher dimension. When the tumor volume reached $20 \mathrm{~mm}^{3}$, mice were divided randomly into four groups with four mice per group (day 0 ). The first group served as a control and received $0.2 \mathrm{ml}$ PBS as vehicle at days 0 and 8 , and $0.1 \mathrm{ml} \mathrm{PBS}$ containing $10 \mathrm{mM} \beta$-mercaptoethanol at days 2, 3, 4, 5 and 10, 11, 12,13 . The second group was injected as group 1 , but received $4 \mathrm{mg} / \mathrm{kg}$ CDDP at day 0 and day 8 . The third group received $8 \mathrm{mg} / \mathrm{kg}$ recombinant His-TRAIL at days 2, 3, 4, 5 and days $10,11,12,13$ and PBS at days 0 and 8 . The fourth group received $4 \mathrm{mg} / \mathrm{kg}$ CDDP at days 0 and 8 and $8 \mathrm{mg} / \mathrm{kg}$ recombinant His-TRAlL at days $2,3,4,5$ and days $10,11,12,13$. All administrations were done intraperitoneally. The initial value for each group (day 0 ) was arbitrarily established as 100 , and all subsequent changes in tumor volume for each group were expressed as a percentage change in comparison with the starting tumor volume [(Tumor volume day 1) $\times 100 /$ (Tumor volume at day 0$)$ ], and are referred as arbitrary tumor volume.

\section{Conflict of interest}

The authors declare no conflict of interest.

Acknowledgements. This work is supported by grants of the Conseil Regional de Bourgogne, the INCa (Institut National du Cancer), Cancéropôle Grand-Est, ANR (Agence Nationale de la Recherche, ANR-06-JCJC-0103 and 07-PCV-0031), and the European Community (ApopTrain Marie Curie RTN) (OM and $\mathrm{EI})$. AM, DM, NL, DL and GJ are supported by fellowships from the Ligue Nationale contre le Cancer, the Ministry of Research and Education, the ARC (Association pour la Recherche sur le Cancer), the INSERM and the Conseil Regional de Bourgogne. We are indebted to Bert Vogelstein for HCT116 Bax-/cell line, to Eric Fourmeau for technical help with in vivo experiments and to Sarah Shirley for critical reading of the manuscript.

1. Ashkenazi A, Holland P, Eckhardt SG. Ligand-based targeting of apoptosis in cancer: the potential of recombinant human apoptosis ligand $2 /$ Tumor necrosis factor-related apoptosis-inducing ligand (rhApo2L/TRAIL). J Clin Oncol 2008; 26: 3621-3630.

2. Merino D, Lalaoui N, Morizot A, Solary E, Micheau O. TRAIL in cancer therapy: present and future challenges. Expert opin ther targets 2007; 11: 1299-1314.

3. Berg D, Lehne M, Muller N, Siegmund D, Munkel S, Sebald W et al. Enforced covalent trimerization increases the activity of the TNF ligand family members TRAIL and CD95L. Cell Death Differ 2007; 14: 2021-2034.

4. Ganten TM, Haas TL, Sykora J, Stahl H, Sprick MR, Fas SC et al. Enhanced caspase-8 recruitment to and activation at the DISC is critical for sensitisation of human hepatocellular carcinoma cells to TRAIL-induced apoptosis by chemotherapeutic drugs. Cell Death Differ 2004; 11(Suppl 1): S86-S96.

5. Lacour S, Micheau O, Hammann A, Drouineaud V, Tschopp J, Solary E et al. Chemotherapy enhances TNF-related apoptosis-inducing Ligand DISC assembly in HT29 human colon cancer cells. Oncogene 2003; 22: 1807-1816.

6. Ndozangue-Touriguine O, Sebbagh M, Merino D, Micheau O, Bertoglio J, Breard J. A mitochondrial block and expression of XIAP lead to resistance to TRAIL-induced apoptosis during progression to metastasis of a colon carcinoma. Oncogene 2008; 27: 6012-6022.

7. LeBlanc H, Lawrence D, Varfolomeev E, Totpal K, Morlan J, Schow P et al. Tumor-cell resistance to death receptor-induced apoptosis through mutational inactivation of the proapoptotic Bcl-2 homolog Bax. Nat Med 2002; 8: 274-281.

8. Sanlioglu AD, Karacay B, Koksal IT, Griffith TS, Sanlioglu S. DcR2 (TRAIL-R4) siRNA and adenovirus delivery of TRAIL (Ad5hTRAIL) break down in vitro tumorigenic potential of prostate carcinoma cells. Cancer Gene Ther 2007; 14: 976-984.

9. Sanlioglu AD, Korcum AF, Pestereli E, Erdogan G, Karaveli S, Savas B et al. TRAIL death receptor-4 expression positively correlates with the tumor grade in breast cancer patients with invasive ductal carcinoma. Int J Radiat Oncol Biol Phys 2007; 69: 716-723.

10. Riccioni R, Pasquini L, Mariani G, Saulle E, Rossini A, Diverio $D$ et al. TRAlL decoy receptors mediate resistance of acute myeloid leukemia cells to TRAlL. Haematologica 2005; 90: 612-624

11. Griffith TS, Chin WA, Jackson GC, Lynch DH, Kubin MZ. Intracellular regulation of TRAIL-induced apoptosis in human melanoma cells. J Immunol 1998; 161: 2833-2840.
12. Merino D, Lalaoui N, Morizot A, Schneider P, Solary E, Micheau O. Differential inhibition of TRAIL-mediated DR5-DISC formation by decoy receptors 1 and 2. Mol Cell Biol 2006; 26: 7046-7055.

13. Llobet D, Eritja N, Encinas M, Llecha N, Yeramian A, Pallares J et al. CK2 controls TRAIL and Fas sensitivity by regulating FLIP levels in endometrial carcinoma cells. Oncogene 2008: 27: 2513-2524.

14. Travert M, Ame-Thomas $\mathrm{P}$, Pangault $\mathrm{C}$, Morizot A, Micheau $\mathrm{O}$, Semana $\mathrm{G}$ et al. CD40 ligand protects from TRAIL-induced apoptosis in follicular lymphomas through NF-kappaB activation and up-regulation of c-FLIP and Bcl-xL. J Immunol 2008; 181: 1001-1011.

15. von Haefen C, Gillissen B, Hemmati PG, Wendt J, Guner D, Mrozek A et al. Multidomain Bcl-2 homolog Bax but not Bak mediates synergistic induction of apoptosis by TRAIL and 5-FU through the mitochondrial apoptosis pathway. Oncogene 2004; 23: 8320-8332.

16. Galligan L, Longley DB, McEwan M, Wilson TR, McLaughlin K, Johnston PG. Chemotherapy and TRAIL-mediated colon cancer cell death: the roles of p53, TRAIL receptors, and c-FLIP. Mol Cancer Ther 2005; 4: 2026-2036.

17. Pavet V, Beyrath J, Pardin C, Morizot A, Lechner MC, Briand JP et al. Multivalent DR5 peptides activate the TRAIL death pathway and exert tumoricidal activity. Cancer res 2010; 70: 1101-1110

18. Soria JC, Smit E, Khayat D, Besse B, Yang X, Hsu CP et al. Phase $1 \mathrm{~b}$ study of dulanermin (recombinant human Apo2L/TRAIL) in combination with paclitaxel, carboplatin, and bevacizumab in patients with advanced non-squamous non-small-cell lung cancer. J Clin Oncol 2010; 28: 1527-1533.

19. Koornstra JJ, Kleibeuker JH, van Geelen CM, Riicken FE, Hollema H, de Vries EG et al. Expression of TRAIL (TNF-related apoptosis-inducing ligand) and its receptors in normal colonic mucosa, adenomas, and carcinomas. I Pathol 2003; 200: 327-335.

20. Ganten TM, Sykora J, Koschny R, Batke E, Aulmann S, Mansmann U et al. Prognostic significance of tumour necrosis factor-related apoptosis-inducing ligand (TRAIL) receptor expression in patients with breast cancer. J Mol Med 2009; 87: 995-1007.

21. Granci V, Bibeau F, Kramar A, Boissiere-Michot F, Thezenas S, Thirion A et al. Prognostic significance of TRAIL-R1 and TRAIL-R3 expression in metastatic colorectal carcinomas. Eur J Cancer 2008; 44: 2312-2318.

22. Spencer SL, Gaudet S, Albeck JG, Burke JM, Sorger PK. Non-genetic origins of cell-to-cell variability in TRAIL-induced apoptosis. Nature 2009; 459: 428-432.

23. Nagane M, Pan G, Weddle JJ, Dixit VM, Cavenee WK, Huang HJ. Increased death receptor 5 expression by chemotherapeutic agents in human gliomas causes synergistic cytotoxicity with tumor necrosis factor-related apoptosis-inducing ligand in vitro and in vivo. Cancer res 2000; 60: 847-853.

24. Nguyen DM, Yeow WS, Ziauddin MF, Baras A, Tsai W, Reddy RM et al. The essential role of the mitochondria-dependent death-signaling cascade in chemotherapy-induced potentiation of Apo2L/TRAlL cytotoxicity in cultured thoracic cancer cells: amplified caspase 8 is indispensable for combination-mediated massive cell death. Cancer J 2006; 12: $257-273$

25. Ruiz-Ruiz C, Lopez-Rivas A. Mitochondria-dependent and -independent mechanisms in tumour necrosis factor-related apoptosis-inducing ligand (TRAIL)-induced apoptosis are both regulated by interferon-gamma in human breast tumour cells. Biochem J 2002; 365 (Part 3): 825-832

26. Wilson TR, McLaughlin KM, McEwan M, Sakai H, Rogers KM, Redmond KM et al. c-FLIP: a key regulator of colorectal cancer cell death. Cancer res 2007; 67: 5754-5762.

27. Mirandola P, Ponti C, Gobbi G, Sponzilli I, Vaccarezza M, Cocco L et al. Activated human NK and CD8+ T cells express both TNF-related apoptosis-inducing ligand (TRAIL) and TRAIL receptors but are resistant to TRAIL-mediated cytotoxicity. Blood 2004; 104 2418-2424.

28. Dumitru CA, Carpinteiro A, Trarbach T, Hengge UR, Gulbins E. Doxorubicin enhances TRAIL-induced cell death via ceramide-enriched membrane platforms. Apoptosis 2007; 12: 1533-1541.

29. Xu L, Qu X, Zhang Y, Hu X, Yang X, Hou K et al. Oxaliplatin enhances TRAIL-induced apoptosis in gastric cancer cells by CBL-regulated death receptor redistribution in lipid rafts. FEBS Lett 2009; 583: 943-948.

30. Longley DB, Wilson TR, McEwan M, Allen WL, McDermott U, Galligan $L$ et al. c-FLIP inhibits chemotherapy-induced colorectal cancer cell death. Oncogene 2006; 25: 838-848.

31. Micheau O, Solary E, Hammann A, Dimanche-Boitrel MT. Fas ligand-independent, FADD-mediated activation of the Fas death pathway by anticancer drugs. JBiol Chem 1999; 274: 7987-7992.

32. Rebillard A, Jouan-Lanhouet S, Jouan E, Legembre P, Pizon M, Sergent O et al. Cisplatininduced apoptosis involves a Fas-ROCK-ezrin-dependent actin remodelling in human colon cancer cells. Eur J Cancer 2010; 46: 1445-1455.

33. Kohler B, Anguissola S, Concannon CG, Rehm M, Kogel D, Prehn JH. Bid participates in genotoxic drug-induced apoptosis of HeLa cells and is essential for death receptor ligands' apoptotic and synergistic effects. PLoS One 2008; 3: e2844.

34. Ullenhag GJ, Mukherjee A, Watson NF, Al-Attar AH, Scholefield JH, Durrant LG. Overexpression of FLIPL is an independent marker of poor prognosis in colorectal cancer patients. Clin Cancer Res 2007; 13: 5070-5075. 
35. Koksal IT, Sanlioglu AD, Karacay B, Griffith TS, Sanlioglu S. Tumor necrosis factor-related apoptosis inducing ligand-R4 decoy receptor expression is correlated with high Gleason scores, prostate-specific antigen recurrence, and decreased survival in patients with prostate carcinoma. Urol Oncol 2008; 26: 158-165.

36. Schneider P. Production of recombinant TRAIL and TRAIL receptor: FC chimeric proteins Methods Enzymol 2000; 322: 325-345.
37. Morgenstern JP, Land H. Advanced mammalian gene transfer: high titre retroviral vectors with multiple drug selection markers and a complementary helper-free packaging cell line. Nucleic Acids Res 1990; 18: 3587-3596.

38. Cheng EH, Wei MC, Weiler S, Flavell RA, Mak TW, Lindsten T et al. BCL-2, BCL-X(L) sequester $\mathrm{BH} 3$ domain-only molecules preventing BAX-and BAK-mediated mitochondrial apoptosis. Mol cell 2001; 8: 705-711.

Supplementary Information accompanies the paper on Cell Death and Differentiation website (http://www.nature.com/cdd) 